\title{
COMPATIBILIDADE ENTRE PSICANÁLISE E LÓGICA
}

\author{
Jorge Luís Gonçalves dos Santos ${ }^{\star}$ \\ Roberto Calazans ${ }^{\star \star}$
}

\begin{abstract}
Resumo
O objetivo deste artigo é demonstrar que entre a psicanálise e o pensamento científico podemos falar em compatibilidade. Para alcançar esse objetivo analisaremos, em um primeiro momento, como a lógica, ao se tornar matemática, se vale de um pensamento plural e não da ilusão de unidade da razão, que seria colocada na lógica clássica como uma conquista absoluta. Após, mostraremos como Freud, em A Interpretação dos Sonhos também coloca, com sua tese sobre o funcionamento do inconsciente, o primado da lógica clássica em questão, principalmente o princípio do terceiro-excluido, o princípio de não contradição e, principalmente, o princípio de identidade.
\end{abstract}

Palavras-chave: Psicanálise. Lógica. Compatibilidade.

\section{Compatibility Between PSYCHOANALYSIS AND LOGIC}

\begin{abstract}
The objective of this article is to demonstrate that between psychoanalysis and the scientific thought we could talk of compatibility. To reach this objective we analyze how logic, when becoming mathematics, takes advantage of a plural thought and no of an illusion of unity of reason, which would be placed in classical logic as an absolute achievement. Next, we will show how Freud, in "The interpretation of Dreams" also places, with his thesis about the functioning of the unconscious, the primacy of classical logic in question, mainly the principles of the third excluded, the non-contradiction, and the principle of identity.
\end{abstract}

Keywords: Psychoanalysis. Logic. Compatibility.

^ Psicólogo formado pela Universidade Federal de São João del Rei. Mestrando do Programa de Pós-Graduação em Teoria Psicanalítica da Universidade Federal do Rio de Janeiro

E-mail: jorgegsantos@yahoo.com.br

$\star \star$ Psicólogo formado pela Universidade Federal do Rio de Janeiro. Mestre e Doutor em Teoria Psicanalítica pela Universidade Federal do Rio de Janeiro. Professor Adjunto do Programa de Pós-Graduação em Psicologia da Universidade Federal de São João del Rei.

E-mail: calazans@ufsj.edu.br 


\section{INTRODUÇÃO}

Sigmund Freud, em 1900, ao escrever A Interpretação dos Sonhos, elabora algumas hipóteses acerca do funcionamento do aparelho psíquico na elaboração onírica, aplicando os resultados de sua pesquisa ao campo que lhe era de interesse: a etiologia das neuroses. Ao afirmar que o sonho é uma realização do desejo, Freud indica que o material psíquico emergente no sonho é o resultado de uma elaboração de pensamentos inconscientes. A aparente obscuridade, a falta de lógica, a insipiente contradição entre os elementos do sonho são então explicados através da distinção entre o processo secundário e o processo primário. Freud considera o conteúdo manifesto e o pensamento latente como duas maneiras diferentes de se estruturar o pensamento que seguem princípios lógicos diferentes. O processo secundário, próximo do pensamento consciencial, se estabelece segundo os princípios da lógica clássica, a saber: o princípio de identidade, o de não-contradição e o do terceiro excluído. Já o processo primário se estrutura em torno de outros princípios, tornando possível aquilo que para a consciência seria contraditório: o princípio de não-identidade e de contradição (FREUD, 1915/1996, p. 191).

Robert Blanché, por sua vez, em A Ciência Atual e o Racionalismo (1983) afirma no desenvolvimento da ciência moderna, os princípios lógicos clássicos são colocados em jogo tanto na física como na via de matematização da lógica conhecida como axiomatização (SINACEUR, 1994, p. 52). Neste desenvolvimento vemos a lógica se tornar matemática, científica, abandonando o primado até então filosófico da questão (DUBUCS, 2001, p. 357). A matematização, seja da ciência, seja da lógica, traz como conseqüência a pluralização da lógica: para cada problema, será desenvolvida uma lógica específica. Exige que uma proposição, para ser científica, siga o que Gaston Bachelard (1996) chama de sentido do problema: para cada problema que é colocado, é necessário um modo próprio de abordá-lo.

Acreditamos que não se trata de mera coincidência que a psicanálise em seu surgimento e a lógica, ao se tornar ciência em seu desdobramento, sigam caminhos semelhantes; afinal, como afirma Jacques Lacan (1966), a psicanálise só pode surgir em um mundo em que a ciência moderna é possível. Por essa razão é que pretendemos nesse artigo demonstrar a compatibilidade entre a psicanálise e lógica contemporânea tomando como ponto de análise a destituição que ambas fazem dos princípios da lógica clássica, abrindo as vias para uma razão plural e não mais presa à ilusão de unidade. Para tal, tanto a ciência como a psicanálise tiveram de admitir a possibilidade de um outro tipo de lógica, diferente daquela sustentada pelos processos conscientes e daquela construída pela ciência clássica.

Como a história da ciência moderna indica-nos a possibilidade de estruturação de uma teoria em função das relações estabelecidas entre os conceitos, como também tentaremos mostrar como a noção de inconsciente elaborada por Freud é logicamente compatível ao Espírito Científico, começaremos nosso artigo expondo os princípios da lógica clássica e a sua destituição pela lógica contemporânea. Depois apontaremos que essa destituição é uma conseqüência e uma 
extensão do advento da atividade científica e própria ao Espírito Científico. E em seguida demonstraremos a compatibilidade da psicanálise com esse modo de pensar apontado para a lógica do inconsciente.

\section{A regulaÇão do Pensamento e as leis lógiCas Clássicas}

Como demonstra Blanché (1983) os princípios fundamentais das leis lógicas que regulariam o curso do pensamento e constituiriam as bases da razão são enumerados como: (1) o princípio de identidade (A é A); (2) o princípio da nãocontradição, que mostra a impossibilidade de algo seja simultaneamente o que é e o que não é (A e não-A); e (3) o princípio do terceiro excluído, que implica uma escolha e a exclusão do impossível (A ou não-A). Já a partir do fim do século XIX a crise dos fundamentos da matemática começa a ameaçar esta estrutura lógica do pensamento; os axiomas matemáticos, quando aplicados aos conjuntos infinitos, não mais garantiam a certeza dos princípios lógicos, sendo que "através de argumentações bastante simples e de uma lógica aparentemente irrepreensível, podia-se demonstrar tanto uma proposição como a sua negação" (BLANCHÉ, 1983, p. 105), o que fere os princípios fundamentais das leis da lógica clássica. A lógica aristotélica, estabelecida sobre um pensamento substancialista, já tinha sido substituída por uma lógica matemática, faltava agora à completa degradação dos princípios da lógica tradicional, tarefa realizada com o desenvolvimento da lógica matemática no século XX.

\section{A pluralidade das lógicas e a Unidade da razão}

A física moderna inaugurou um universo infinito, no qual as velhas estruturas clássicas de pensamento não se mostravam mais adequadas (KOYRÉ, 1992). A ciência moderna, em seu Espírito (BACHELARD, 1996) despe-se então das inadequações dos quadros lógicos habituais, percebendo que outras formas de se estruturar o pensamento são possíveis e necessárias, sendo propriamente o que lhe permite construir seu objeto e dar sua ordem de produção. O Espírito Científico não permite que afirmações a priori sejam estabelecidas. $\mathrm{O}$ mesmo ocorre com a lógica, quando ela se torna uma atividade científica e rompe com seu passado filosófico.

O princípio do terceiro excluído, "segundo o qual duas proposições opostas contraditoriamente não podem ser as duas falsas, de modo que da falsidade de uma se pode concluir a verdade de outra" (BLANCHÉ, 1983, p. 115), foi o primeiro a sofrer o abalo da nova lógica. A dúvida colocada é se, entre a afirmação e a negação, pode-se ou não realizar uma suspensão de juízo, se há lugar entre elas para o que haveria de indeterminado. Em outros termos: será possível o uso de regras da lógica clássica, feita para o uso de conjuntos finitos, no tratamento de conjuntos infinitos? No caso de conjuntos infinitos, o princípio do terceiro excluído não pode ser aplicado com segurança. Se, por exemplo, tivermos um conjunto finito de bolas, e as colocarmos num saco, poderemos seguramente inferir duas proposições de equivalência: (1) "é falso que todas as bolas sejam pretas", e (2) "é verdadeiro que existe pelo menos uma bola que não é preta". Passando de uma 
afirmação para a outra, podemos facilmente concluir a existência de uma bola que não seja preta no saco. Não podemos, entretanto, enunciar proposições semelhantes ao se tratar de conjuntos infinitos justamente em razão de que, no que se refere aos conjuntos infinitos, o emprego de palavras como "todos", "nenhum", bem como a designação "existe", passam a não fazer mais sentido.

Se tomarmos como outro exemplo um conjunto qualquer de números, e questionarmos se aí se encontra a série $0,1,2,3,4,5,6,7,8,9$ poderemos nos portar de duas formas: através de um pensamento clássico ou um moderno. Browver (1927) já tinha apontado à necessidade de situar os níveis de problemas em que se trabalha, vendo que a atitude do pensamento frente à questão se coloca de maneira diferente caso se trate de um conjunto infinito ou não. Imaginemos que se trate de um conjunto infinito. Seguindo ainda um pensamento dualista, a lógica tradicional obrigar-nos-ia a responder se a série se encontra verdadeiramente ou se não no conjunto. Se a resposta for negativa, ou seja, se afirmar que a série ali não se encontra, esse pensamento será denunciado como "absurdo": ele terá que provar, indiretamente, a existência da série de números apontada, tanto pela exclusão do terceiro como pela necessidade de reconhecer o verdadeiro através do falso, o que ele não pode fazer. Só restaria então, ao nosso matemático clássico, afirmar que a série se encontra no conjunto - o que também seria equívoco, pois ele também não é capaz de indicar onde ela se encontra.
A ciência rejeita a idéia de um significado e uma verdade em si, independentes da sua apreensão e caracteriza-se pelo significado e pela verdade de um enunciado através da possibilidade de verificá-lo efetivamente. Também recusa o direito de extrapolar os princípios cujo valor tenha sido controlado e confirmado num domínio de certa ordem de grandeza, e de estendê-los, sem precaução, a novos domínios de proporções diferentes da precedente: não há legislação à priori, absoluta e universalmente válida (BLANCHÉ, 1983, p.117).

Assim como as geometrias não-euclidianas, o valor deste sistema lógico é apreendido pela coerência interna entre seus elementos. Certos raciocínios que antes podiam ser tidos como verdadeiros, são agora proibidos, significando o enfraquecimento das bases da logística clássica. A ciência físico-matemática de Galileu, após três séculos, se autoriza, dentro de próprio campo, a empreender uma maneira lógica e calculatória de fornecer a ordem de produção de um objeto.

Restará ao pensamento moderno o princípio da contradição? Na verdade até mesmo esse princípio será descartado pela ciência moderna, pelo sistema de Lukasiewicz (1967). Entretanto, gostaríamos de atentar para o fato de que a contradição é apenas uma condição lógica: uma segunda lógica poderia simplesmente ignorar a relação contraditória e estabelecer uma função entre seus elementos. "Poderíamos manter o princípio somente com a condição utilizá-lo como uma relação funcional entre os termos da proposição" (Lukasiewicz, 1967, p. 57). 
Em 1920, Lukasiewicz elabora um sistema trivalente que admite as proposições verdadeiro/falso através dos respectivos valores 0 e 1 , acrescentando uma terceira designação de valor igual a $1 \frac{1}{2}$. Tal sistema rejeitava simultaneamente o princípio do terceiro excluído como o caso da contradição, visto que ao valor $1 / 2$ atribuemse os casos que não se inserirem no par contraditório verdadeiro/ falso (0 ou 1). Esse terceiro valor desmentiria a afirmação da lógica clássica que estabeleceu a falsidade de uma proposição a partir de uma equivalência entre duas proposições contraditórias, caso que, como vimos através do sistema de Lukasiewicz, seria designada não como falsa, mas como referente ao terceiro valor (1/2).

Não tarda para surgir, a partir do sistema de Lukasiewicz outros que não coadunavam com a lógica clássica, “(...) trivalentes, quadrivalentes, ou n-valentes, chegando até a comportar um número infinito de valores, como a lógica probabilitária de Reichenbach" (BLANCHÉ, 1983, p.123). Se foi através da matematização, e mais especificamente da geometria, que a física pode encontrar os parâmetros de sua objetividade, é através dela que os novos axiomas lógicos da ciência encontram sua força. A geometria já "tinha posto em evidência que, num sistema onde os axiomas são independentes, pode-se sempre modificar ou retirar um (ou vários) para ver, por simples curiosidade teórica, quais as modificações que daí resultariam no corpo dos teoremas" (BLANCHÉ, 1983, p.124). Isso demonstra como os teoremas não devem ser admitidos como proposições absolutas, dados estabelecidos a priori, mas como axiomas lógicos que são estabelecidos de acordo com o que se procura: "o verdadeiro e o falso, dizem-nos, não são senão mais ou menos prováveis e a lógica deve adaptar-se para poder ter em conta estas nuances" (BLANCHÉ, 1983, 126).

Temos como conseqüência desses abalos nos princípios da lógica a queda do terceiro princípio: o de identidade. Com efeito, se eu não posso mais me ater estritamente ao princípio do terceiro excluído, se eu posso afirmar algo como sendo simultâneo, ignorando desse modo o princípio de não-contradição, é muito difícil sustentar uma identidade que seja perene, que não vá depender de todo um trabalho de articulação e que pode, em função de como os elementos são organizados, aparecer um ou outro evento. É o fim do substancialismo em lógica e o início do pensamento realmente funcional. Com isso a lógica, como afirma Dubucs (2001), deixa de ser um assunto de filosofia e passa a ser um assunto eminentemente matemático e, por conseguinte, estritamente científico: "esta disciplina deixou indiscutivelmente de ser uma parte da filosofia, e acabou por constituir antes um setor, hoje cada vez menos marginal, das próprias matemáticas" (BLANCHÉ, 2001, p.357).

A tese clássica da unidade incondicional da razão é finalmente abandonada: não há uma única lógica independente de seu conteúdo ou, em outras palavras, para cada domínio é preciso apelar aos conteúdos das lógicas que lhe são adequados, tendo cada teoria sua própria lógica. Wittgeinstein (apud BLANCHÉ, 1983) já tinha denunciado o vazio das formas lógicas; estabelecer uma lógica significa propor um jogo entre os signos, manejados por regras de sintaxe que lhe são próprios. É em relação à escolha dessa sintaxe que certo enunciado 
irá ser dotado ou não de sentido, demonstrando sua possibilidade lógica ou não. A ciência moderna trabalha a relação lógica como um sistema coerente de leis deliberadamente expressas.

\section{A CiênCIA E O RACIONALismo MODERNo}

Escolher uma lógica de pensamento segundo sua adequação é fazer com que novas regras de pensamento surjam adaptadas a objetos bem determinados, o que, em suma, significa produzir um instrumento científico especializado. A ciência não conseguiu, através da lógica clássica, atingir o cerne de uma razão perfeita e impecável, ela descobriu as lógicas como um instrumento que se colocava à disposição da razão, uma maneira calculatória de dar a ordem de produção de um objeto. O que importa neste campo de problemas são sistemas de equações, cujas noções iniciais são somente uma das soluções possíveis.

É necessário notar que, quando falamos da destituição da lógica clássica no quadro da ciência moderna, não estamos afirmando que é comprometida qualquer possibilidade de estabelecer relações lógicas. Ao contrário, abrem-se as possibilidades.

O racionalismo contemporâneo se despoja de qualquer conhecimento que seja concebido a priori ou estruturado por uma razão que se coloca como imutável. É impossível conceber que o conhecimento venha de fora e que a função do espírito é somente impor sua forma. De qualquer maneira, a evolução dos conceitos científicos mostrou que os a priori tradicionais da filosofia e da ciência clássica não eram o bastante para definir a razão.

Mas ao invés de descartá-los, são considerados a partir de uma ótica mais ampla, como apenas um domínio da razão:

Quando se verifica que a nova ciência, longe de destruir a antiga, conseguiu, pelo contrário, estender prodigiosamente $o$ seu domínio, ultrapassando os obstáculos que lhe impunham hábitos seculares de pensamento, pretende-se antes levar ao ativo da razão não só as transformações a que ela submeteu os seus princípios, como as vitórias que soube obter para si mesma. A lição a se tirar daqui, é que, consequentemente, o racionalismo dos princípios é que deve ser melhorado (BLANCHÉ, 1983, p.138).

E o que pode então significar a experiência dentro no racionalismo contemporâneo? Ela se assemelha a posição a que tinham colocado os empiristas, quando enfatizaram demasiadamente a experiência na formação dos princípios científicos? É certo que a razão esta atrelada com a experiência, mas de qualquer maneira é o espírito que recebe ativamente a impressão da experiência. A razão não está numa relação de dependência da experiência sensível; representada a certa escala, a sensibilidade se coloca como um limite cujas contrariedades são transpostas pela razão. De qualquer maneira, respondendo ao empirismo, mudase pouco as coisas deslocar para a experiência a idéia de um a priori absoluto. 
O racionalismo moderno trata a formulação de um a priori como relativo e funcional, não como universal. Também é impossível abandonar as próprias regras, pois, sem elas não poderíamos falar de razão; tudo seria relegado ao puro arbítrio. Há então uma junção entre os termos do constituído e do constituinte, "ou ainda, para mudar de comparação, que os aperfeiçoamentos do instrumento não teriam sentido sem uma idéia diretriz do operário, ou que a noção de órgão implica a de função" (BLANCHÉ, 1983, p.142). O racionalismo moderno, passando da razão constituída à razão constituinte, coloca o próprio movimento do pensamento como exigência permanente: "o intellectus ipse situa-se aquém das estruturas, só exige que haja uma estruturação, ele é o dinamismo organizador que cria para si próprio os seus meios e seu fim" (BLANCHÉ, 1983, p.144).

\section{CONSEQÜÊNCIAS}

A ciência se especifica ao se estabelecer em um nível de operação reprodutível, chamado experimentação (ULLMO, 1967). A ciência moderna ensinanos, no curso de sua história, que um objeto não tem uma apreensão a priori, sua definição é dada por uma ordem de produção, calculada através de formulações conceituais. Nem mesmo a experiência científica pode ter qualquer valor se não for definida como uma (re)produção possibilitada por um índice calculatório. $\mathrm{O}$ conceito se apura com a experiência, mas não é, de maneira alguma, determinado por ela. É o próprio pensamento que permite com que sejam possíveis a experiência e a definição de um objeto. Poderíamos então colocar algumas questões no que concerne a conceitualização das teorias. O que permite que a ciência construa seus conceitos ou o que, exatamente, lhes confere o estatuto de verdade? $\mathrm{Ou}$, como já vimos, se uma teoria científica é possibilitada por uma lógica que estabelece a função entre conceitos, qual é a sua proximidade daquilo que ela concebe com o que ela produz?

Se entendermos o pensamento como aquele que estrutura uma realidade ou a ciência como aquela que produz a realidade de seu objeto, "nossa concepção do conceito implica ser este sempre estabelecido numa aproximação que não deixa de ter relação com o que nos impõe, como forma, o cálculo infinitesimal" (LACAN, 1964/1985, p. 25). A ciência moderna trabalha com dois limites: o mundo físico e a infinidade dos números. Mas ao invés de tratar esses limites contraditórios, ela postula uma lógica onde os dois podem ser possíveis. A física moderna é aquela que liga a matemática mais abstrata à física do real mais profundo: "se o conceito se modela, com efeito, por uma aproximação da realidade que ele foi feito para apreender, só por um salto, por uma passagem ao limite que, é que ele chega a se realizar" (LACAN, 1964/1985, p. 25). A atividade científica para realizar uma experiência deve, portanto, expressar abertamente a função que ali foi estabelecida, ou seja, dizer quais são as relações entre os elementos que sempre que forem calculados a partir de certa lógica operarão de maneira específica.

As distinções entre as atividades a científica e a psicanalítica aparecem na medida em que o campo da precisão não é concernente ao do sujeito. Se Freud pretende tratar deste sujeito, seu campo de problemas se situará em outra região 
que não a científica: a histérica diz a Freud que nada sabe de seu sintoma, e demanda a cura, ou seja, um saber que lhe falta. Mas não poderemos deixar de enfatizar as semelhanças existentes na estruturação dos conceitos psicanalíticos e os científicos. Quando Freud examina os sintomas histéricos e não vê ali nenhuma afecção orgânica, torna-se claro que a causa dos sintomas deveria ser procurada num campo de problemas correspondente ao psíquico; a conversão histérica era somente o final de um processo de pensamento.

Ora, não serão estes os mesmos impasses que a lógica encontrou no desenvolvimento de sua teoria? A lógica não só pôde ser concebida moderna quando abandonou elaborações conceituais impregnadas de velhos hábitos de pensamento? Longe de serem condições necessárias a ao pensamento científico, alguns elementos do pensamento clássico foram considerados obstáculos epistemológicos quando não puderam ser aplicadas no domínio do microfísico, assim como o principio de substância, identidade e não-contradição. Se as realizações do microfísico foram concebidas pela estrutura lógica de um pensamento, a escala do mundo macroscópico (a que a intuição sensível recobre) também deve ser concebida como modalização de uma outra lógica, que contrasta com a primeira. Uma observação que novamente salientamos que esses princípios do pensamento clássico não foram banidos do campo da física moderna, apenas destituídos, considerados como obstáculos se não restritos ao nível do macrofísico.

E em que tudo isso se coaduna com a psicanálise? O sintoma não poderia ser a expressão de uma lógica de pensamento que os processos conscientes, tão acostumados com a lógica habitual da intuição sensível, ignoram? Se nos detivermos a uma lógica do consciente, nada sobre o sintoma poderá ser afirmado. Mas se nos permitirmos estabelecer um outro nível lógico, onde processos inconscientes são permitidos, poderemos, segundo afirma Freud, livrar o sujeito do sintoma em questão. Percebe-se, que da mesma maneira que a ciência foi obrigada a introduzir um outro processo lógico em suas elaborações (para poder então constituir seu objeto), Freud insere no aparelho psíquico uma segunda lógica de pensamento, no qual aquilo que seria ininteligível no nível da consciência poderia ser explicado por seus processos (inconscientes). Com a possibilidade da existência de uma pluralidade de lógicas na ciência, algo é nítido: uma logística é escolhida em detrimento de outra, que, por sua vez, assume o valor de duvidosa, ignorada, desconhecida. A física só pôde conhecer verdadeiramente a ordem de produção de um objeto quando percebeu que o conhecimento do que é verdadeiro ou do que é falso só pode ser estabelecido em relação a um desconhecido. Se a realidade física, para a ciência, só pode ser concebida através de uma logística conceitual que se imponha sem ignorar a possibilidade que exclui; no mesmo sentido, a realidade do sintoma só pode ser definida através de uma lógica de pensamento consciente que não percebe a possibilidade que exclui - que a histérica, sobre a sexualidade, diz nada saber.

Torna-se claro a razão da histérica afirmar nada saber sobre seu sintoma apesar deste afetar o seu corpo sem qualquer constrangimento físico (FREUD, 1895/1996). O procedimento teórico e clínico de Freud para responder a questão sobre a etiologia das neuroses é explicar o sintoma por uma lógica de pensamento 
(inconsciente) na qual o sujeito não se reconhece. Podemos então aproximar a histérica da posição ocupada pelos praticantes dos princípios da física clássica: ambos ignoram que a realidade pela qual pensam ser atingidos (tanto o sintoma quanto as colocações a priori) é um produto da sua própria atividade do pensamento. O que poderia equivocá-los? Já vimos como os princípios filosóficos da ciência clássica foram equivocados com os postulados da ciência moderna. E o sujeito, à parte de toda essa discussão científica, quem o equivoca?

\section{A interpretaÇão doS SONHOS}

Quando Freud considera os sonhos como formações do inconsciente, ele acaba por introduzir, além do conteúdo manifesto em que a elaboração onírica é apresentada, uma nova classe de material psíquico através do qual poderia se apreender o trabalho de um sonho, o pensamento onírico latente. Se o conteúdo manifesto do sonho é apresentado de uma maneira confusa e ilógica, ele passa a ser considerado uma espécie de substituto para outros processos de pensamento, em que os elementos constituintes do sonho aparecem de maneira inteligível. Para explicar o funcionamento da elaboração onírica, Freud trata os sonhos como produto da ação de dois sistemas psíquicos, um que constrói o desejo expresso no sonho, e outro que produz uma distorção nessa expressão, impondo uma censura sobre o desejo onírico. Se algo se apresenta em um sonho como contraditório, ilógico ou aflitivo para a consciência, ao mesmo tempo ele é apreendido como a realização de um desejo por parte do sistema inconsciente. A consciência seria então considerada como um processo psíquico específico, e não como o único processo psíquico possível. Com a observação acerca dos sonhos, Freud indica que pensamentos mais complexos e inteligíveis podem ocorrer sem a participação da consciência. Na verdade, a consciência passa a ser somente um resultado dos processos psíquicos inconscientes, de modo que os pensamentos inconscientes se tornam mais gerais do que os pensamentos conscientes, uma vez que dão conta do conteúdo e daquilo que escapa ao que é consciente.

Se afirmamos que a possibilidade da estruturação da teoria psicanalítica só advém com a realização de uma outra lógica, inconsciente, cujos processos permanecem ignorados e desconhecidos pela lógica de pensamento consciente, mas que, entretanto, mantém uma influência decisiva sobre seus processos, os problemas que se levantam na teoria psicanalítica são tanto sobre o funcionamento do processo psíquico que transforma o pensamento latente do sonho no conteúdo manifesto, quanto quais são os motivos necessários para que haja tal transformação. Os sonhos têm seus conteúdos modificados pela censura, mas se acham associativamente ligadas ao conteúdo que substituem.

Pode ser demonstrado que tudo de que podemos libertarnos são idéias intencionais que nos são conhecidas; assim que houvermos feito isso, idéias intencionais desconhecidas, inconscientes, tomam conta e, daí por diante, determinam o curso das idéias involuntárias (FREUD, 1900, p. 563). 
Neste sentido, se um elemento psíquico se achar ligado a outro por uma relação frouxa ou objetável, ali também se achará presente um outro tipo de ligação mais legítima e profunda, que se encontra sujeita a censura. Então, em vez de ocorrer uma associação perfeitamente normal no conteúdo onírico, apresenta-se uma associação superficial e aparentemente absurda. O sonho tem que, acima de tudo, fugir da censura e, para isso, fazer uso de um processo conhecido como deslocamento até o ponto em que ocorra uma modificação dos valores psíquicos.

Assim, se acompanharmos os deslocamentos ocorridos entre o conteúdo apresentado pelo sonho e o pensamento onírico, veremos que há uma clara divergência entre seus pontos centrais. Na formação de um sonho, é o deslocamento que faz com que elementos com uma dose elevada de valor psíquico possam ser tratados como se nenhum interesse peculiar incidisse sobre eles, despojando os elementos de alto valor psíquico de sua intensidade. Mas, por outro lado, o deslocamento também opera para que elementos de baixo valor psíquico sejam investidos por meio da sobredeterminação, atribuindo novos valores a elementos de baixa intensidade psíquica. A elaboração onírica, portanto, não é mais irracional ou incompleta em comparação com o pensamento de vigília; ela é inteiramente diferente. Só poderemos supor uma arbitrariedade apresentada pelo conteúdo onírico se restringirmos aos elementos apresentados pela consciência, aqueles que já foram alvos de uma censura. Assim, pode-se demonstrar que os processos psíquicos são bastante determinados; "se um elemento se apresenta como indeterminado por certo encadeamento de pensamento, sua determinação é imediatamente efetuada por outro" (FREUD, 1900, p.548).

O deslocamento coloca, de saída, em questão a idéia de princípio de identidade. O deslocamento não visa identificar para distinguir o que é do que não é; ele é decorrente de um trabalho de produção de valores até então insuspeitados.

Percebendo que a análise dos pensamentos oníricos se desdobrava em muitos mais elementos do que o próprio conteúdo apresentado pelo sonho, Freud indica que na elaboração onírica também há o trabalho de condensação, onde cada elemento do sonho se dissocia em várias direções, conduzindo a muitas outras representações a partir de fragmentos isolados. Pela condensação, grupos de idéias são expressos por um conteúdo intermediário que penetra no conteúdo dos sonhos como por um ato de conciliação, de tal modo que ali verifica um trabalho de determinação múltipla. Se desdobrarmos as idéias representadas em um sonho, perceberemos que cadeias de pensamentos inconscientes que pareciam não ter ligação com o sonho se acham condensados em alguma idéia representada em seu conteúdo, estando presentes durante sua formação e desempenhando funções em sua elaboração. Pode-se seguir, pelas vias associativas, tanto de um elemento do sonho para vários pensamentos do sonho, como de um pensamento do sonho para vários elementos do conteúdo onírico. A condensação, por sua vez não respeita nem o princípio de não-contradição e muito menos o princípio do terceiro excluído.

Desta maneira, não encontraremos o sonho estruturado isoladamente de acordo com um pensamento subjacente, mas sim por uma gama de pensamentos 
que influi nos elementos do sonho, que são, por sua vez, multiplamente determinados em relação àqueles pensamentos. Desta maneira, tanto o conceito de deslocamento quanto o de condensação são de extrema importância para entendermos como a lógica inconsciente determina os processos conscienciais não por uma seqüência linear, onde se poderia afirmar uma simples relação de causa-efeito - o que remeteria a uma teoria do tipo legalista (KOJËVE, 1990). Na psicanálise, os conceitos são considerados de maneira funcional, de acordo com o Espírito Científico, onde o valor de um conceito só é determinado pela posição em que ele ocupa em relação aos outros conceitos da própria teoria. Elaborar o conceito de inconsciente e traçar a maneira como os elementos do sonho podem ser por ele influenciado, mesmo que uma idéia recalcada atinja a consciência somente as custas de uma série de modificações, significa dizer que este processo somente acontece por uma relação de determinação múltipla, impossível de ser delineada antes do próprio trabalho de interpretação.

Por meio do deslocamento, condensação e da determinação múltipla, é que as relações contraditórias podem ser estabelecidas num sonho sem que se respeite às relações admitidas pela lógica consciencial. "O que é reproduzido pelo aparente pensamento no sonho é o tema dos pensamentos do sonho e não a relação mútua entre eles, cuja asserção constitui o pensamento" (FREUD, 1900, p. 300). Se num sonho [este é um exemplo bastante utilizado por Freud] duas idéias ocorrem em seqüência imediata, como, no caso, "a" e "b", não devemos supor que há uma continuidade temporal ou uma relação causal entre elas; o que se impõe é um vínculo temático, o que faria com que aquelas sílabas fossem pronunciadas como uma única sílaba: "ab". Outro exemplo que Freud se utiliza é sobre a defesa de um homem que foi acusado por um de seus vizinhos de ter devolvido danificada uma chaleira que lhe havia sido emprestada: primeiramente o homem afirmou que tinha devolvido a chaleira em perfeitas condições, em segundo, disse que a chaleira já tinha um buraco quando ele a tomou emprestada, e que, por último, que ele nunca havia pedido emprestada uma chaleira para seu vizinho. A questão que Freud coloca é que se apenas "uma" dessas afirmativas fosse verdadeira, o homem teria de ser absolvido, mas que de maneira nenhuma ele poderia utilizar "todas" alternativas ao mesmo tempo, já que se resultaria uma contradição. Desta mesma forma, as alternativas que se costumam inserir nos sonhos também não precisam se submeter às relações lógicas estabelecidas pela consciência; elas costumam a preencher todas as possibilidades suscitadas pelas idéias, mesmo que elas sejam excludentes entre si. A categoria dos contrários e dos contraditórios é altamente desconsiderada no que diz respeito aos sonhos, os elementos contrários podem ser combinados em uma unidade ou mesmo representados como uma coisa só.

Para representar um aparelho psíquico composto por duas instâncias regidas por funcionamentos lógicos diferentes, Freud o representa como modelo de um aparelho reflexo. Esse aparelho teria seu inicio a partir de um pólo receptor de estímulos, uma extremidade sensória, apta a receber as percepções, e um outro que terminaria em enervações, caracterizando e uma extremidade que dá acesso à própria atividade motriz. Contudo, entre os dois sistemas, haveria um terceiro 
que transformaria as excitações do primeiro sistema em traços permanentes, retendo as modificações entre os elementos. Nesse sistema intermediário residiriam os chamados traços mnemônicos, que, a partir de diminuições de resistências e de caminhos facilitadores, transmitiriam as excitações de um elemento mnemônico para o outro. O sistema inconsciente estaria então localizado nessas interações estabelecidas entre os elementos mnemônicos. Ao afirmar que o sonho é uma "realização (disfarçada) de um desejo (suprimido ou recalcado)" (FREUD, 1900, p.172), Freud coloca que o sistema inconsciente é o ponto de partida da formação onírica. Se durante o dia o acesso aos elementos inconscientes recalcados à consciência é barrado pela censura, durante a noite eles podem ter acesso à consciência através de modificações em seus conteúdos. O sonho então teria sua força motivadora em um impulso impregnado de desejo, representando uma própria satisfação para esse impulso. Freud explica esse fato dizendo que durante o sono, a excitação percorre o aparelho psíquico no sentido "regressivo", de modo que as excitações, durante o sono, não são deslocadas para a extremidade motora, mas em direção aos próprios elementos mnemônicos. Assim se pode explicar o caráter alucinatório do sonho, na medida em que nesse movimento regressivo há um investimento na imagem mnemônica, de modo que o pensamento é conduzido até a vivificação sensorial fornecidas pelas imagens mnemônicas.

No que condiz ao estudo das estruturas neuróticas, o processo de formação dos sonhos realiza uma grande contribuição para a teoria psicanalítica, uma vez que a produção dos sintomas também se encontra ligada a processos psíquicos que seriam "irracionais" se comparados com pensamentos conscienciais. Os sintomas são formados do mesmo modo que certos pensamentos são apresentados no conteúdo dos sonhos: através da condensação e pela formação de compromissos, por cadeias associativas e através desprezo pelas contradições. Porém, o que Freud indica é que esses pensamentos seriam considerados como normais se não estivessem submetidos a um tipo de tratamento "anormal", e, principalmente, se não fossem remetidos a um desejo inconsciente, que, estando sobre poder do recalque, transferiu uma parcela de sua quantidade de energia para eles.

Já vimos no modelo de aparelho psíquico descrito por Freud o estabelecimento de dois tipos de sistema no interior do aparelho, um primeiro, que tem sua atividade dirigida no sentido a se ver livre das quantidades de excitação, segundo as bases do princípio do prazer, e um segundo, que evita um dispêndio de investimento desnecessário inibindo a descarga e transformando o investimento em baixas quantidades de energia. O que ocorre é que o segundo sistema (o que é considerado por Freud como processo secundário) somente investe em uma idéia se ela pode inibir o desenvolvimento do desprazer que dela pode advir, segundo o direcionamento tanto do princípio do prazer quanto do princípio de menor dispêndio de energia. Se o processo primário tenta estabelecer uma "identidade perceptiva" com a experiência de satisfação, a fim de ocasionar uma descarga da quantidade de excitação acumulada, o processo secundário tenta estabelecer uma "identidade de pensamento" com aquela experiência (FREUD, 1900). O pensamento consciencial, portanto, não seria nada além do que um caminho indireto à experiência de satisfação, se estabelecendo mais pelos caminhos de ligações 
entre essas idéias do que pelas intensidades por elas apresentadas. Como parte do processo primário, os impulsos impregnados de desejos que são originados na infância e apresentam conteúdos que seriam tomados como contraditórios de acordo as idéias presentes no pensamento secundário. Esses impulsos também não podem ser destruídos. O sentido do problema aqui levantado é que "a realização desses desejos não geraria um afeto de prazer, mas sim de desprazer e é precisamente essa transformação de afeto que constitui aquilo que chamamos de recalque" (FREUD, 1900, p. 642). Se o desejo inconsciente recalcado efetua uma tentativa de forçar seu caminho com sua excitação para o sistema consciente, há, por parte do segundo sistema, um contra-investimento, até que por meio de transferência da energia de investimento produzida pelo desejo recalcado possa chegar a uma espécie de acordo entre os dois sistemas pela produção do sintoma.

Ao trabalhar com os sonhos, Freud pôde perceber que os pensamentos que possibilitam sua formação são impulsos impregnados de desejos, que, pelo próprio relaxamento da censura produzida pelo sono, abrem seu caminho a consciência através de certas distorções em seus conteúdos. A elaboração onírica traz, então, para a teoria psicanalítica, um importante exemplo de como processos inconscientes de pensamento podem produzir efeitos, através do deslocamento de investimentos, nos processos conscienciais, de maneira que se pode afirmar a existência de dois tipos de lógicas que, mesmo mantendo um funcionamento independentemente, se relacionam mutuamente. É exatamente nesse ponto que podemos afirmar que Freud se aproxima do Espírito Científico quando realiza a sua teoria sobre uma perspectiva de um pluralismo lógico. O estudo dos sonhos também é de extrema importância ao demarcar que os sintomas pelos quais os neuróticos eram atingidos, não se relacionariam com fatos traumáticos reais, mas a conteúdos fantasmáticos, produtos da própria atividade de pensamento. Não obstante, um impulso inconsciente que fora recalcado, retorna sobre a forma de sintoma, frente ao qual o paciente pergunta sobre a causa, sem saber (ou seja, ignorando) que o sintoma é a expressão de sua própria atividade de pensamento.

\section{Conclusão}

A psicanálise é o correspondente no campo ético deste pensamento que surge com o nascimento da ciência moderna. Nas lógicas matematizadas é possível que sistemas incompatíveis entre si sejam verdadeiros, desde que integrem sistemas diferentes. Os princípios que regem os sistemas são apenas formulados, e não se tratam de afirmações. O mesmo é verificado na psicanálise: as estruturas neurótica, perversa ou psicótica são alguns exemplos. A verdade trazida pelo pensamento psicanalítico está em mostrar que a consciência é um tipo de lógica possível, mas não a única. A psicanálise, baseada na experiência que lhe é própria, procura evidenciar estes modos possíveis, mas não pretende afirmar uma verdade, unicidade ou supremacia de nenhum deles pela simples razão de que tal coisa não existe; a validade de um pensamento é independente da verdade de seu conteúdo. 


\section{REFERÊNCIAS}

BACHELARD, G. A formação do espírito cientifico. Rio de Janeiro: Contraponto, 1996.

BLANCHÉ, R. A ciência atual e o racionalismo. Lisboa: Res, 1983.

DUBUCS, J. A lógica depois de Russel. In: . BLANCHÉ, R. História da lógica. Lisboa: Edições 70, 2001. p.357-394.

FREUD, S. Estudos sobre a histeria (1895). In: . Obras psicológicas completas. Rio de Janeiro: Imago, 1996, v. II, p. 364. Edição Standard Brasileira.

. A interpretação dos sonhos (1900). In: . Obras psicológicas

completas. Rio de Janeiro: Imago, 1996, v. IV-V, p. 670 . Edição Standard Brasileira.

- O inconsciente (1915). In: . Obras psicológicas completas. Rio de Janeiro: Imago. 1996, v. XIV, p. 191-248. Edição Standard Brasileira.

KOJÈVE, A. L'idée du déterminisme dans la physique classique et dans la physique moderne. Paris: Librairie Génerale Française, 1990.

KOYRÉ, A. Considerações sobre Descartes. Lisboa: Presença, 1992.

LACAN, J. O Seminário, Livro 11: Os quatro conceitos fundamentais da psicanálise (1964). Rio de Janeiro: J. Zahar, 1985.

. Do sujeito enfim em questão (1966). In: J. Zahar, 1998. . Escritos. Rio de Janeiro:

SINACEUR, H. Jean Cavaillès: Philosophie mathemátique. Paris: P.U.F., 1994.

ULLMO, J. O pensamento cientifico moderno. Coimbra: Coimbra, 1967.

Recebido em: maio de 2006.

Aceito em: Junho de 2007. 